Revista Brasil. Bot., V.32, n.3, p.441-454, jul.-set. 2009

\title{
Dinâmica espaço-temporal (1962-2006) das fitofisionomias em unidade de conservação do Cerrado no sudeste do Brasil
}

\author{
EDUARDO DA SILVA PINHEIRO ${ }^{1}$ e GISELDA DURIGAN 2,3
}

(recebido: 25 de maio de 2008; aceito: 07 de abril de 2009)

\begin{abstract}
Spatial and temporal dynamics (1962-2006) of Cerrado vegetation types in a protected area, southeastern Brazil). Recent studies indicate that after protection from human pressures (fire, cattle grazing and agriculture), structural changes occur in the cerrado vegetation, changing open physiognomies into more closed savannas. We analyzed the dynamics of vegetation types along 44 years, at Assis Ecological Station, one of the rare conservation units protecting the cerrado biome in the southeastern São Paulo State, Brazil, with the aim of characterizing and quantifying those changes in space and time. Protected against human pressures since a long time, field observations have shown an upgrade of local cerrado physiognomies, through a successional process whose structural climax can be a forest physiognomy, with a continuous arboreal stratum. The dynamics of the vegetation types was analyzed by using aerial photographs (1962, 1984 and 1994), Quick Bird satellite images (2006) and field surveys. During this 44 years period, field physiognomies were reduced from $23 \%$ to less than $1 \%$ of the total area studied. In the other extreme, woodland savanna increased from $53 \%$ to $91 \%$ of the area. Changes did not happen at the same rhythm across the area, and that is apparently correlated to microclimate and edaphyc differences. We believe that field and savannic physiognomies initially existing were mostly maintained due to heavy human pressures, constraining the secondary succession towards an edapho-climatic climax of greater biomass. Confirming the observations of cerrado areas elsewhere, protection against fire, cattle grazing and agriculture allowed the evolution of open vegetation types into more closed ones, tending to be locally extinct the first if new disturbances do not occur. Consequences of these changes related to management strategies, biodiversity conservation and carbon sink are discussed.
\end{abstract}

Key words - Brazilian Savanna, cerrado physiognomies, human pressures, secondary succession, vegetation dynamics

RESUMO - (Dinâmica espaço-temporal (1962-2006) das fitofisionomias em unidade de conservação do Cerrado no sudeste do Brasil). Estudos recentes indicam que em áreas de Cerrado protegidas das atividades antrópicas ocorre uma evolução estrutural de fitofisionomias abertas para outras mais fechadas, com tendência ao desaparecimento das primeiras. Analisou-se a dinâmica das fisionomias do Cerrado ao longo de 44 anos, na Estação Ecológica de Assis, SP, uma das poucas unidades de conservação do bioma no sudeste do Brasil, com o objetivo de caracterizar e quantificar possíveis tranformações fisionômicas no tempo e no espaço. Protegida de pressões antrópicas por longo tempo, observações de campo têm indicado um adensamento da vegetação em toda a área, rumo a um clímax de estrutura florestal. Para realizar este estudo foram utilizadas aerofotos (1962, 1984 e 1994), imagens "QuickBird" (2006) e reconhecimento de campo. Durante o período compreendido por este estudo, a área ocupada pelas fisionomias campestres foi reduzida de $23 \%$ para menos de $1 \%$ da área estudada, enquanto, no outro extremo do gradiente fisionômico, a proporção correspondente ao cerradão aumentou de 53\% para $91 \%$. O ritmo de adensamento da vegetação não foi o mesmo em toda a área, estando, aparentemente, correlacionado com a posição topográfica e diferenças edáficas. Acreditamos que as fisionomias campestres e savânicas inicialmente existentes eram mantidas em decorrência de pressões antrópicas, que impediam a evolução rumo a um clímax edafo-climático de maior fitomassa. Confirmando o que tem sido observado em outros locais, a proteção contra o fogo e a suspensão de atividades agropastoris possibilitaram uma evolução gradativa das formações abertas (campo, campo cerrado e cerrado típico) para outras mais fechadas (cerrado denso e cerradão), tendendo as primeiras ao desaparecimento, caso não ocorram novos distúrbios. As conseqüências dessas transformações, relacionadas com estratégias de manejo, conservação da biodiversidade e fixação de carbono são discutidas.

Palavras-chave - dinâmica da cobertura vegetal, fitofisionomias, pressões antrópicas, savana, sucessão secundária

\section{Introdução}

Apesar de ter sido incluído entre as 25 áreas consideradas críticas para conservação da diversidade

1. Universidade Federal do Amazonas - UFAM, Departamento de Geografia, Campus Universitário, 69077-000 Manaus, AM, Brasil.

2. Instituto Florestal Floresta Estadual de Assis, Caixa Postal 104, 19802-970 Assis, SP, Brasil.

3. Autor para correspondência: giselda@femanet.com.br biológica no mundo ("hotspots"), devido à sua riqueza e à alta pressão antrópica a que vem sendo submetido (Myers et al. 2000), o Cerrado tem sido alvo de poucas ações concretas e estudos visando a sua conservação. Ao mesmo tempo em que o desmatamento na Amazônia recebe ampla publicidade, a destruição do Cerrado é negligenciada pela mídia (Ratter et al. 2006) e, naturalmente, há desequilíbrio na distribuição de recursos e esforços destinados àquelas ações. Estudos 
recentes mostram que permanecem intactos apenas $20 \%$ da cobertura original do Cerrado em todo o país e somente $2,2 \%$ deste bioma estão inseridos em áreas protegidas (Machado et al. 2004). No Estado de São Paulo a situação é ainda mais alarmante, restando menos de $7 \%$ da cobertura original e apenas $0,5 \%$ protegidos em unidades de conservação (Durigan 2006). Mesmo estas áreas, supostamente protegidas, ainda sofrem impactos diversos, como incêndios freqüentes, gramíneas invasoras e pressões decorrentes do isolamento.

Além da rápida e drástica redução de área, pressões antrópicas diversas ameaçam permanentemente as áreas remanescentes. Tais pressões, cada vez mais intensas e freqüentes em decorrência, sobretudo, de atividades agropecuárias, determinaram significativos danos ambientais aos ecossistemas do Cerrado (Alger \& Lima 2003). Klink \& Machado (2005) destacam, entre as conseqüências da ocupação desordenada do Cerrado, a fragmentação de habitats, a redução da biodiversidade, a invasão por espécies exóticas, a erosão dos solos, a poluição de aqüíferos, a alteração no regime de queimadas, o desequilíbrio no ciclo do carbono e, possivelmente, modificações climáticas regionais.

Os problemas e ameaças apontados pelos estudiosos são, em geral, atribuídos à intensificação da ação antrópica nas décadas recentes. Todavia, há registros da presença humana nas áreas de domínio do Cerrado praticamente durante todo o Holoceno e há evidências de que, durante todo esse período, episódios de fogo fizeram parte da história e da ecologia dessa vegetação (Dean 1996), de modo que o fogo é, possivelmente, um fator cujos efeitos já foram incorporados na adaptação das espécies e na dinâmica do ecossistema.

Estudos recentes têm demonstrado a evolução estrutural de fisionomias abertas para outras mais fechadas, com maior fitomassa, em diversas áreas de cerrado em diferentes regiões do Brasil (Goodland \& Ferri 1979 em Emas, SP, Durigan et al. 1987 em Assis, SP, Ratter et al. 1988 em Angatuba, SP, Ratter 1992, no Distrito Federal, Durigan \& Ratter 2006 e Pinheiro 2006, em Corumbataí, SP). Todos esses estudos associam a evolução estrutural à supressão de pressões antrópicas, especialmente pastejo e fogo, sugerindo que o estado anterior seria um ecossistema cujas características manter-se-iam relativamente estáveis desde que inalteradas as pressões antrópicas, mas que tende a evoluir se protegido. Esses estudos conduzem ao enquadramento do cerrado como um disclímax por alguns autores (Rizzini 1979, Fernandes 2000) ou clímax antrópico, expressão não reconhecida no Brasil, mas utilizada em outros ecossistemas ao redor do mundo (e.g. Bouchard \& Domon,1999).

Resultados semelhantes, demonstrando a evolução estrutural das fisionomias mediante supressão de impactos, foram obtidos em outros tipos de vegetação e em outras regiões do planeta, podendo ser citados os estudos de Archer et al. (1988) em vegetação campestre no Texas, EUA, Carmel \& Kadmon (1999) e Kadmon \& Harari-Kremer (1999) em campos de Israel, Bowman et al. (2001) em uma matriz composta por Eucalyptus e savanas na Austrália. Tais estudos conduzem a um consenso de que o pastejo e o fogo são importantes fatores de pressão sobre esses ecossistemas, interferindo negativamente na expansão de arbustos e árvores sobre áreas campestres.

Todavia, se, por um lado, a intensificação das pressões antrópicas pode conduzir à perda de biodiversidade e desequilíbrio do ecossistema, por outro lado, a supressão total das perturbações em formações campestres e savânicas pode ocasionar transformações importantes. Spurr \& Barnes (1980) consideram que, para ecossistemas nos quais o fogo foi um fator de seleção atuante em longo prazo, a supressão do fogo seria tratada como distúrbio. As transformações decorrentes da supressão das pressões antrópicas podem modificar as condições ótimas para a sobrevivência e reprodução de muitas espécies da fauna e da flora (Durigan \& Ratter 2006), favorecer o estabelecimento de competição inter e intra-específica por recursos que não eram escassos antes (e.g. luz) e, assim, acarretar perdas de biodiversidade ou, pelo menos, modificações na composição e na estrutura das comunidades, pela imigração de novas espécies, adaptadas à nova condição (Franco 2005). Nos estágios iniciais de desenvolvimento, espécies vegetais do cerrado investem predominantemente em sistemas radiculares, para garantir sua sobrevivência à seca e às queimadas, o que resulta em um reservatório de nutrientes. Este mecanismo também permite um rápido aumento da fitomassa em áreas protegidas do fogo (Franco 2005). Por essas razões, alguns estudiosos defendem o manejo do fogo visando à conservação da diversidade biológica do Cerrado (Coutinho 1990, Ramos-Neto \& Pivello 2000, Miranda et al. 2004, Pivello 2005).

A dinâmica das fisionomias da vegetação natural do Cerrado na Estação Ecológica de Assis (EEcA), ao longo de 44 anos, foi objeto do presente estudo, para verificar se o processo de evolução estrutural das fisionomias que vem ocorrendo em outras áreas protegidas se repete nesta unidade de conservação. São discutidas as implicações que tais transformações podem ter sobre o manejo e a conservação da diversidade de espécies e ecossistemas 
na área de estudo e em outras áreas remanescentes de Cerrado.

\section{Material e métodos}

Caracterização da área de estudo - A Estação Ecológica de Assis, unidade de proteção integral dos recursos naturais, foi criada em 1992, com área de 1.312,18 ha, com o principal objetivo de preservar uma amostra dos ecossistemas do Cerrado na região Sudoeste do Estado de São Paulo. A área foi desmembrada da então Estação Experimental de Assis, do Instituto Florestal do Estado de São Paulo, cuja finalidade maior era a pesquisa em silvicultura com espécies exóticas. Embora a criação da Estação Ecológica seja relativamente recente, a área vinha sendo protegida do pastoreio e das queimadas, tendo cessado a agricultura e a exploração de madeira desde 1959, quando passou a ser de propriedade do Estado. Em 2002 a área da unidade foi ampliada, com a incorporação de antigos talhões de Pinus e Eucalyptus, passando a abranger 1.760,64 ha. Apenas a área original, ocupada por vegetação nativa (1.312,18 ha), foi objeto deste estudo.

A Estação Ecológica de Assis está localizada entre as coordenadas $22^{\circ} 33^{\prime} 20^{\prime \prime}$ a $22^{\circ} 37^{\prime} 41^{\prime \prime}$ latitude Sul e $50^{\circ} 24^{\prime} 4,8^{\prime \prime}$ a $50^{\circ} 21^{\prime} 27^{\prime \prime}$ longitude Oeste de Greenwich, no Planalto Ocidental paulista, em uma região com relevo suave-ondulado, em altitudes que variam entre 510 e 596 m. A litologia constitui-se de arenitos do Grupo Bauru, da Formação Adamantina (Almeida et al.1981). Os solos no interior da área protegida são do tipo Latossolo Vermelho Distrófico nas partes mais elevadas (zonas de interflúvio) e Argissolo Vermelho-Amarelo Eutrófico e Argissolo Vermelho-Amarelo Distrófico no terço inferior das vertentes (Bognola et al. 1996).

A EEcA está inserida em uma zona de transição entre os tipos climáticos Cwa e Cfa, segundo a classificação de Köppen (1948), caracterizada como subtropical, com chuvas concentradas no verão e estação seca no inverno, com duração variável; as médias anuais de temperatura e precipitação são $21,8{ }^{\circ} \mathrm{C}$ e $1.400 \mathrm{~mm}$, respectivamente. Durante o inverno podem ocorrer geadas, as quais reduzem a biomassa viva da vegetação do cerrado e modificam a flora, ao privilegiar as populações de espécies tolerantes ao frio, especialmente nos fundos de vales (Brando \& Durigan 2004).

Mapeamento da vegetação - Para a quantificação da área ocupada pelas diferentes fitofisionomias da vegetação natural no interior da EEcA, foram utilizadas aerofotos dos anos de 1962 (1:25.000), 1984 (1:35.000), 1994 (1:25.000) e imagens com alta resolução espacial de 2006, do satélite "QuickBird" (QB). As imagens QB, pancromática e multiespectral, foram fundidas pelo método "Gram-Schmidt", disponível no aplicativo ENVI 4.3 (Research Systems Inc. - RSI 2006). Para ortorretificar a imagem QB, utilizou-se o modelo função racional descrito por Tao \& $\mathrm{Hu}(2001)$.

As aerofotos digitais de cada ano foram mosaicadas utilizando-se o aplicativo "Image Registration and
Mosaicking" (REGEEMY) (Fedorov et al. 2003). Para esta tarefa foi aplicada uma transformação Afim, utilizando-se apenas a parte central das aerofotos. Posteriormente, cada mosaico foi georreferenciado, tendo como base a imagem "QuickBird".

As fitofisionomias mapeadas foram classificadas com base em observações de campo, na medida do possível, de acordo com o sistema proposto por Ribeiro \& Walter (1998) para a vegetação do Cerrado.

Para extrair as informações dos produtos de sensoriamento remoto empregaram-se técnicas de interpretação visual, baseadas em elementos usuais, tais como brilho, cor, textura, forma, tamanho, contexto, padrão e tamanho (Lillesand \& Kiefer 2000). As feições foram interpretadas e digitalizadas na tela do computador, em uma escala média de 1:3.500, utilizando-se o aplicativo ArcMap 9.1 (ESRI 2004).

Para as fitofisionomias mapeadas pela imagem atual, estimou-se a cobertura de copas do estrato arbóreo (porcentagem do terreno coberta pela projeção das copas), adaptando-se o método de intercepção de linhas (Canfield 1941), que foi aplicado nos dados de sensoriamento remoto. Assim, a partir das aerofotos e imagens, em cada fitofisionomia de cerrado mapeada foram traçados 10 transectos, cada um com $50 \mathrm{~m}$ de comprimento (extensão real lançada na imagem pelas coordenadas geográficas), e calculada a porcentagem média de cobertura arbórea sobre a linha. Os transectos foram lançados em locais bem definidos das fitofisionomias de cerrado, conforme as características de interpretação visual utilizadas no estudo. Na etapa final do mapeamento, um segundo trabalho de campo foi realizado para verificar a exatidão temática dos mapas gerados.

Para a interpretação das fisionomias mapeadas em 1962 e 1984 recorreu-se, como ferramenta auxiliar, a depoimentos de antigos funcionários do Instituto Florestal e moradores da vizinhança.

\section{Resultados e discussão}

As fitofisionomias identificadas e mapeadas na EEcA (figura 1, tabela 1) foram as seguintes:

Campo limpo úmido - Vegetação de ambiente ripário, que ocupa terrenos úmidos com drenagem deficiente ou lençol freático pouco profundo. A vegetação herbácea é predominantemente composta por gramíneas e ciperáceas.

Cerrado ralo - Este tipo fitofisionômico, também denominado campo cerrado, é mais aberto do que o cerrado típico. $\mathrm{O}$ estrato arbóreo não ultrapassa dois a três metros de altura e o estrato graminoso é contínuo, com elementos lenhosos esparsos. De acordo com as análises das imagens, a cobertura média de copas nesta fisionomia foi de $10,5 \%( \pm 4,4 \%)$. 

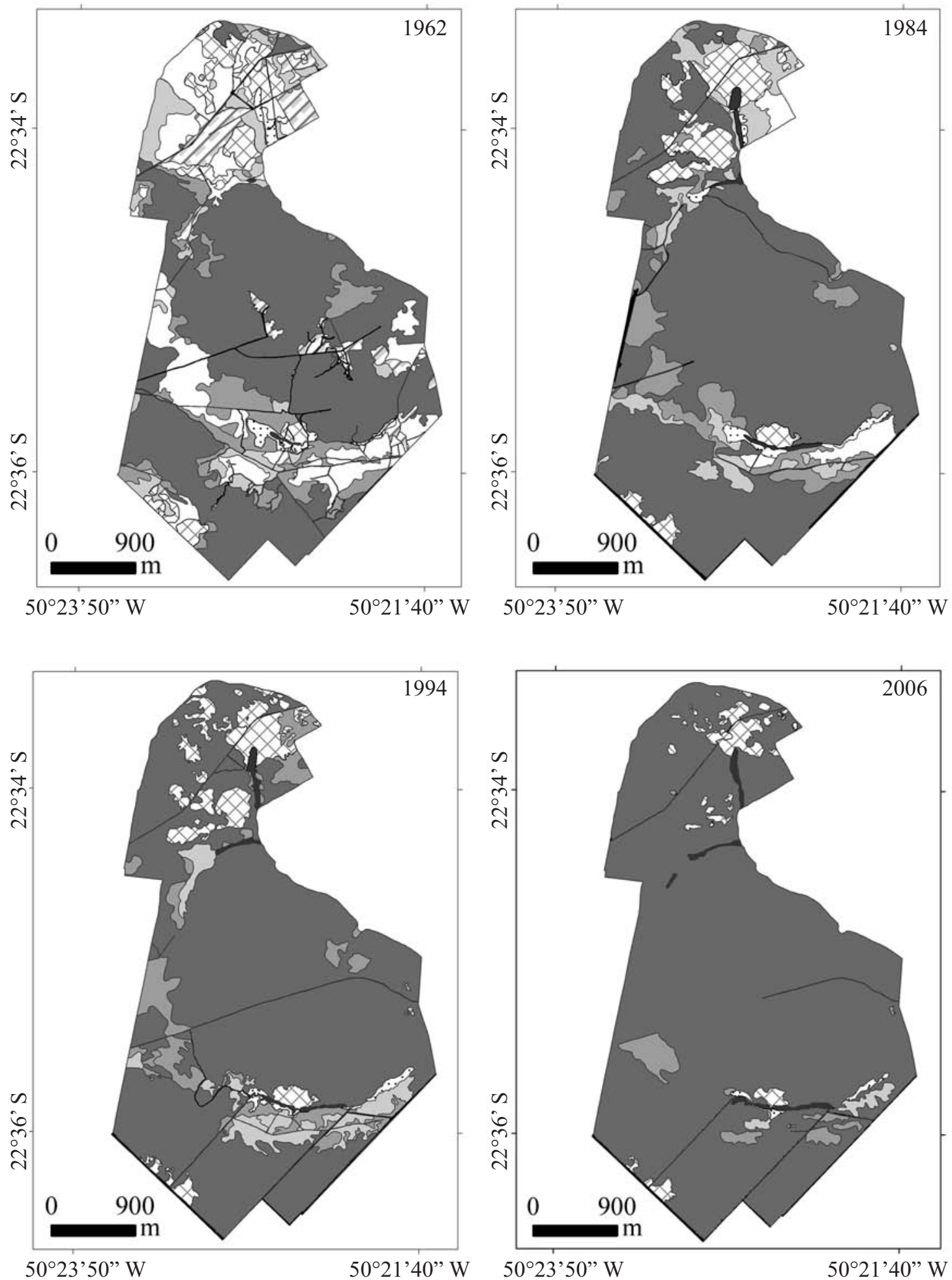

Figura 1. Modificações na cobertura vegetal por diferentes tipos fisionômicos na Estação Ecológica de Assis, SP, no período

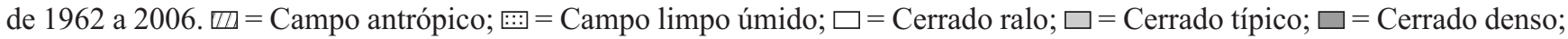
$\square=$ Cerradão; $\boldsymbol{\square}=$ Mata ciliar; $\otimes=$ Invasão (Pteridium arachnoideum); - = Estrada/caminho/aceiro.

Figure 1. Changes in the vegetation physiognomies distribution at Assis Ecological Station, state of São Paulo, Brazil, from 1962 to 2006. $\mathbf{m}=$ Anthropic grassland; $:$ : $=$ Wet grassland; $\square=$ Sparse savanna; $\square=$ Typical savanna; $\square=$ Dense savanna; $\square=$ Woodland savanna; $\boldsymbol{\square}=$ Riparian forest; $\mathbf{\otimes}=$ Invasion (Pteridium arachnoideum); $-=\mathrm{Road} /$ firebreak. 
Tabela 1. Área ocupada (ha e porcentagem) pelos diferentes tipos fitofisionômicos na área de estudo, no período de 1962 a 2006 (Estação Ecológica de Assis, Município de Assis, Estado de São Paulo).

Table 1. Area occupied (ha and percentage) by distinct vegetation types at the studied area from 1962 to 2006 (Estação Ecológica de Assis, State of São Paulo, Brazil).

\begin{tabular}{|c|c|c|c|c|c|c|c|c|}
\hline \multirow{3}{*}{ Classe } & \multicolumn{8}{|c|}{ Área ocupada por cada unidade de mapeamento } \\
\hline & \multicolumn{2}{|c|}{1962} & \multicolumn{2}{|c|}{1984} & \multicolumn{2}{|c|}{1994} & \multicolumn{2}{|c|}{2006} \\
\hline & ha & $\%$ & ha & $\%$ & ha & $\%$ & ha & $\%$ \\
\hline Campo antrópico & 74,36 & 5,9 & 1,41 & 0,1 & 0,00 & 0,0 & 0,00 & 0,0 \\
\hline Campo limpo úmido & 18,69 & 1,5 & 13,05 & 1,0 & 8,73 & 0,7 & 4,66 & 0,4 \\
\hline Cerrado ralo & 194,11 & 15,4 & 32,93 & 2,6 & 0,00 & 0,0 & 0,00 & 0,0 \\
\hline Cerrado típico & 82,07 & 6,5 & 86,87 & 6,9 & 66,86 & 5,3 & 10,54 & 0,8 \\
\hline Cerrado denso & 126,89 & 10,1 & 112,77 & 8,9 & 98,68 & 7,8 & 32,33 & 2,6 \\
\hline Cerradão & 673,74 & 53,4 & 899,20 & 71,3 & 974,97 & 77,3 & $1.115,68$ & 91,4 \\
\hline Mata ciliar & 3,69 & 0,3 & 8,30 & 0,7 & 9,53 & 0,8 & 11,04 & 0,9 \\
\hline Invasão (Pteridium arachnoideum) & 71,16 & 5,6 & 93,43 & 7,4 & 90,73 & 7,2 & 39,18 & 3,1 \\
\hline Estrada/caminho/aceiro & 16,05 & 1,3 & 12,81 & 1,0 & 11,25 & 0,9 & 10,32 & 0,8 \\
\hline Total & $1.260,76$ & 100,0 & $1.260,76$ & 100,0 & $1.260,76$ & 100,0 & $1.260,76$ & 100,0 \\
\hline
\end{tabular}

Cerrado típico - O solo é coberto por gramíneas, ervas e subarbustos e o estrato arbóreo é descontínuo. Este tipo fisionômico apresentou cobertura arbórea média de $46,3 \%$ ( $\pm 8,9 \%)$. Este valor, apesar de relativamente alto, está de acordo com a classificação de Ribeiro \& Walter (1998), que descrevem o cerrado típico com cobertura arbórea entre $20 \%$ e 50\%. Esses autores, no entanto, não explicitam o método utilizado para estimar a cobertura arbórea, o que dificulta comparações para esta e outras fisionomias.

Cerrado denso - É um tipo de vegetação mais baixa e mais aberta do que o cerradão, com estrato arbóreo descontínuo, mas com estrato graminoso inexistente, sendo o piso densamente coberto por ervas e arbustos. A cobertura arbórea média foi de 70,4\% ( $\pm 7,9 \%)$, valores um pouco acima da classificação proposta por Ribeiro \& Walter (1998), ou seja, de 50\% a 70\%. Segundo aqueles autores, esse é o tipo fisionômico mais denso e alto entre as fisionomias agrupadas como cerrado sentido restrito. Normalmente, segundo Durigan et al. (2004), encontrase o cerrado denso em pequenas áreas de transição do cerrado típico para o cerradão.

Cerradão - Fisionomia florestal, em que a vegetação arbórea forma um estrato contínuo, normalmente com mais de $90 \%$ de cobertura, e a altura média das árvores varia entre 8 e $15 \mathrm{~m}$. No presente estudo, a cobertura média de copas neste tipo fisionômico foi de $100 \%$.
Mata ciliar - Vegetação arbórea densa, em terrenos permanentemente úmidos, com cobertura de copas chegando a $90 \%$, que está de acordo com Ribeiro \& Walter (1998).

Além das fisionomias mencionadas, que puderam ser enquadradas na classificação de Ribeiro \& Walter (1998), outras três classes temáticas também foram mapeadas, uma vez que ocupam áreas significativas no interior da unidade de conservação, a saber:

Campo antrópico - Vegetação com predomínio de plantas herbáceas, poucas arbustivas e praticamente nenhuma arbórea. Os campos mapeados caracterizam-se como áreas antropizadas, que foram utilizadas como pastagens ou cultivo agrícola (milho e café), localizadas ao norte da atual Estação Ecológica.

Invasão pela samambaia Pteridium arachnoideum (Kaulf.) Maxon - Este tipo de vegetação aparece nas imagens com textura lisa, em tons de cinza claro a médio. Nas aerofotos de 1962 e 1984 observam-se poucos indivíduos arbóreos associados às áreas com samambaias, sendo possível identificar um adensamento de árvores nas datas posteriores, 1994 e 2006.

Estrada/caminho/aceiro - Feições lineares, desprovidas de vegetação arbórea, facilmente identificáveis nos dados de sensoriamento remoto. Compreende o leito das estradas e caminhos e uma faixa ao longo de suas 
margens e ao longo do perímetro da unidade, em que são efetuadas roçadas periódicas para prevenção de incêndios.

Os resultados do mapeamento demonstram que, durante o período analisado, de 44 anos, houve alterações significativas na cobertura vegetal da EEcA. A principal modificação observada foi o adensamento contínuo da vegetação, com áreas abertas de campo sendo aos poucos ocupadas por fisionomias mais fechadas de cerrado (figura 1, tabela 1). Outras pesquisas sobre dinâmica da cobertura vegetal com dados de sensoriamento remoto, em zonas de interface entre florestas e savanas ou campos, mostram resultados semelhantes aos obtidos neste estudo (Archer et al. 1988, Carmel \& Kadmon 1999, Bowman et al. 2001, Oliveira \& Pillar 2004, Pinheiro 2006, Durigan \& Ratter 2006 e Marimon et al. 2006). Nessas pesquisas há um consenso de que o avanço das fisionomias florestais sobre formações campestres é explicado pela situação climática favorável às primeiras, e que a eliminação do pastejo e queimadas são fatores importantes para a expansão de formações florestais.

Pesquisas tratando especificamente da vegetação de cerrado também indicam que as modificações no regime de queimadas resultam em diferentes fisionomias (Hoffmann 1998; Moreira 2000), alterando a proporção de plantas herbáceas e lenhosas e até mesmo a flora, com imigração ou extinção de espécies. $\mathrm{O}$ aumento da freqüência de queimadas sobre vegetação lenhosa conduz a fisionomias mais abertas, devido às altas taxas de mortalidade, alterações de recrutamento e favorecimento da vegetação rasteira (Miranda \& Sato 2005).

Se, por um lado, maior freqüência de queimadas resulta em aumento da proporção de espécies não lenhosas no cerrado, por outro lado, a total supressão do fogo pode ser considerada uma forma de intervenção nos processos ecológicos naturais em savanas. Moreira (2000) verificou que a proteção contra queimadas faz aumentar a abundância de espécies lenhosas e de espécies sensíveis ao fogo. Diante dessas constatações, alguns estudiosos da conservação do cerrado (como Coutinho 1990, Ramos-Neto \& Pivello 2000, Miranda et al. 2004 e Pivello 2005) defendem queimadas esporádicas como estratégia de manejo para favorecer a manutenção de formações campestres e preservar a biodiversidade.

$\mathrm{Na}$ área atualmente ocupada pela Estação Ecológica de Assis, segundo depoimentos de antigos funcionários e vizinhos, o uso do fogo era freqüente como prática de limpeza de áreas para cultivo ou pastoreio, limitando, certamente, a regeneração das plantas lenhosas e o incremento de fitomassa. Após a desapropriação da área pelo Estado, em 1959, foram praticamente suspensas as perturbações, com dois episódios registrados de incêndio, o primeiro atingindo cerca de 50 ha em 1985 e o segundo queimando menos de 10 ha em 2004 (registros não publicados), sendo as áreas atingidas inferiores a $5 \%$ da área total estudada.

Com a proteção da área, as fisionomias campo antrópico e campo cerrado, que em 1962 ocupavam $21,3 \%$ da área em estudo, não existiam mais nas imagens de 1994 e 2006, tendo sido substituídas por cerradão (figuras 2-5) ou, nas partes mais baixas das vertentes, por cerrado denso (figuras 6-9). O campo limpo úmido perdeu espaço, em parte para o cerrado típico, mas predominantemente para as matas ciliares, tendo sua área reduzida a um quarto da extensão inicial.

Em diversos trechos da área de estudo, verificouse um adensamento gradativo da vegetação, durante o período analisado de 44 anos, com o cerrado ralo (campo cerrado) evoluindo para cerrado típico e, depois, para cerrado denso ou cerradão (figuras 2-9). O elevado número de caminhos identificados nas aerofotos de 1962 evidencia ações antrópicas intensas em períodos anteriores, possivelmente associadas ao pastejo, que foram interrompidas quando a área passou a ser administrada pelo Estado. Como resultado, observa-se a rápida redução dos campos já nas duas primeiras décadas (tabela 1, figura 1), quando comparadas as aerofotos de 1962 e 1984. Em 1984, os elementos lenhosos já se regeneravam sobre os campos, embora em alguns locais tenham proliferado as samambaias (Pteridium arachnoideum).

Entre os anos de 1962 e 1984, observa-se aumento das áreas ocupadas por samambaias, mas, a partir de 1994 este processo de invasão vem sendo revertido (tabela 1, figuras 10-13). Verifica-se, nas fotos de 1962, a existência de alguns poucos indivíduos lenhosos no interior das áreas invadidas. Nos períodos subseqüentes, a densidade e a cobertura de copas das árvores aumentaram gradativamente sobre as samambaias, de modo que entre 1994 e 2006 a área ocupada pela espécie invasora reduziu-se a menos da metade (tabela 1). Em campo, verificou-se que as samambaias estão diminuindo consideravelmente sob as árvores, possivelmente em decorrência do sombreamento, uma vez que a espécie é exigente em luz (Marrs et al. 2000).

As espécies de gênero Pteridium, embora possam ter respostas distintas em diferentes locais, persistem por períodos longos, provavelmente devido aos efeitos competitivos diretos que têm com outras espécies (Marrs et al. 2000). Belinato \& Matos (2003) demonstraram que Pteridium aquilinum (L.) Kuhn representa um perigo para a regeneração natural de dez espécies normalmente 
utilizadas em reflorestamentos na Mata Atlântica. Essas samambaias impedem a sucessão secundária, com efeitos negativos essencialmente sobre o sistema radicular das plântulas de espécies arbóreas.

A reocupação das áreas invadidas por Pteridium arachnoideum pelas espécies arbóreas do cerradão parece, portanto, contrariar o que tem sido observado em outras regiões. É possível que este processo observado na EEcA esteja associado à alta resiliência usualmente atribuída à vegetação de cerrado. Estudos de ecologia e dinâmica de comunidades nas áreas de cerrado ocupadas por $P$. arachnoideum são necessários, para que possam
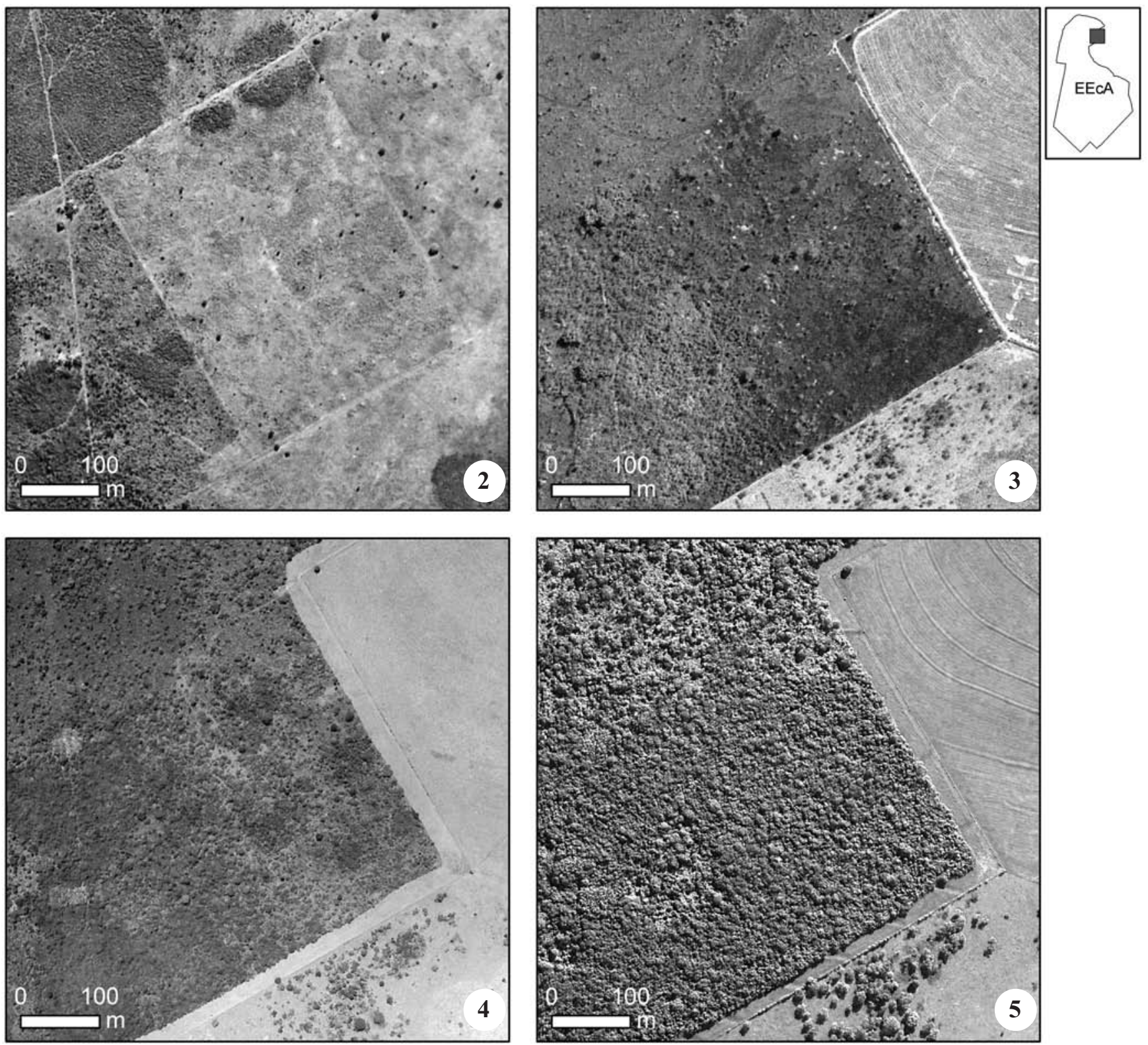

Figuras 2-5. Alterações no tipo fisionômico em um mesmo local, no período de 1962 a 2006, em que o campo antrópico em 1962 (2) evoluiu para cerrado ralo em 1984 (3), cerrado denso em 1994 (4) e cerradão em 2006 (5). Aerofotos (2, 3 e 4), imagem QuickBird (5) (Estação Ecológica de Assis, Município de Assis, Estado de São Paulo).

Figures 2-5. Changes in the vegetation physiognomy at the same site, from 1962 to 2006, where antropic grassland in 1962 (2) was replaced by sparse savanna in 1984 (3), dense savanna in 1994 (3) and woodland savanna in 2006 (5). Aerophotos (2, 3 and 4), QuickBird image (5) (Estação Ecológica de Assis, State of São Paulo, Brazil). 
ser explicados os processos ecológicos que estão condicionando a reversão da invasão por esta espécie.

Embora sejam relevantes as evidências de que a ação antrópica e os incêndios sejam fatores limitantes para a expansão de tipos vegetacionais florestais sobre vegetações campestres ou savânicas (Archer et al.
1988, Carmel \& Kadmon 1999, Bowman et al. 2001, Moreira 2000, Oliveira-Filho \& Ratter 2002, Pinheiro 2006, Durigan \& Ratter 2006), as explicações para tais alterações não estão esgotadas, devendo ser analisados outros possíveis fatores, tais como tipo de solo, microclima e disponibilidade de luz, como condicionantes desse
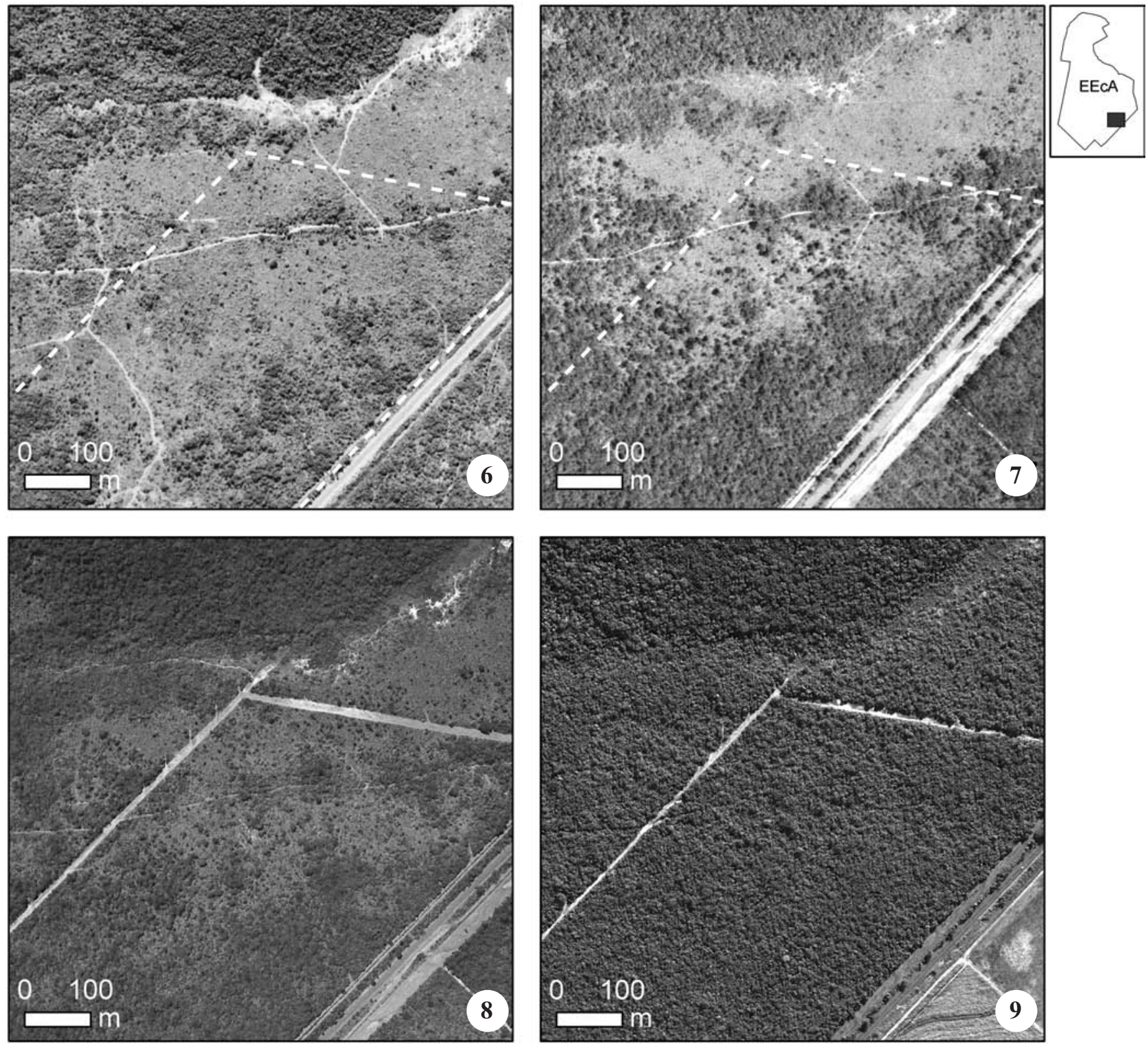

Figuras 6-9. Modificações no tipo fisionômico em um mesmo local, no período de 1962 a 2006, em que a vegetação de cerrado ralo (6 e 7) evoluiu para cerrado típico (8) e depois, para cerrado denso (9). Aerofotos (6, 7 e 8), imagem QuickBird (9) (Estação Ecológica de Assis, Município de Assis, Estado de São Paulo).

Figures 6-9. Changes in the vegetation physiognomy at the same site, from 1962 to 2006, where sparse savanna (6 and 7) changed into typical savanna (8) and then to dense savanna (9). Aerophotos (6, 7 and 8), QuickBird image (9) (Estação Ecológica de Assis, State of São Paulo, Brazil). 
processo. Além dos fatores ambientais e antrópicos mencionados, o tempo para que uma comunidade em fase inicial de sucessão secundária atinja a fase de equilíbrio pode depender também da distância da fonte de propágulos (Henriques 2005). Esta fase de equilíbrio (estabilização da biomassa por unidade de área) seria representada pelo cerradão em boa parte das regiões de domínio do Cerrado (Ratter et al. 2006).

No caso da Estação Ecológica de Assis, verificase que a resiliência é variável entre fitofisionomias e entre trechos da unidade. A sucessão rumo ao cerradão tem sido mais lenta nas áreas ocupadas por samambaias
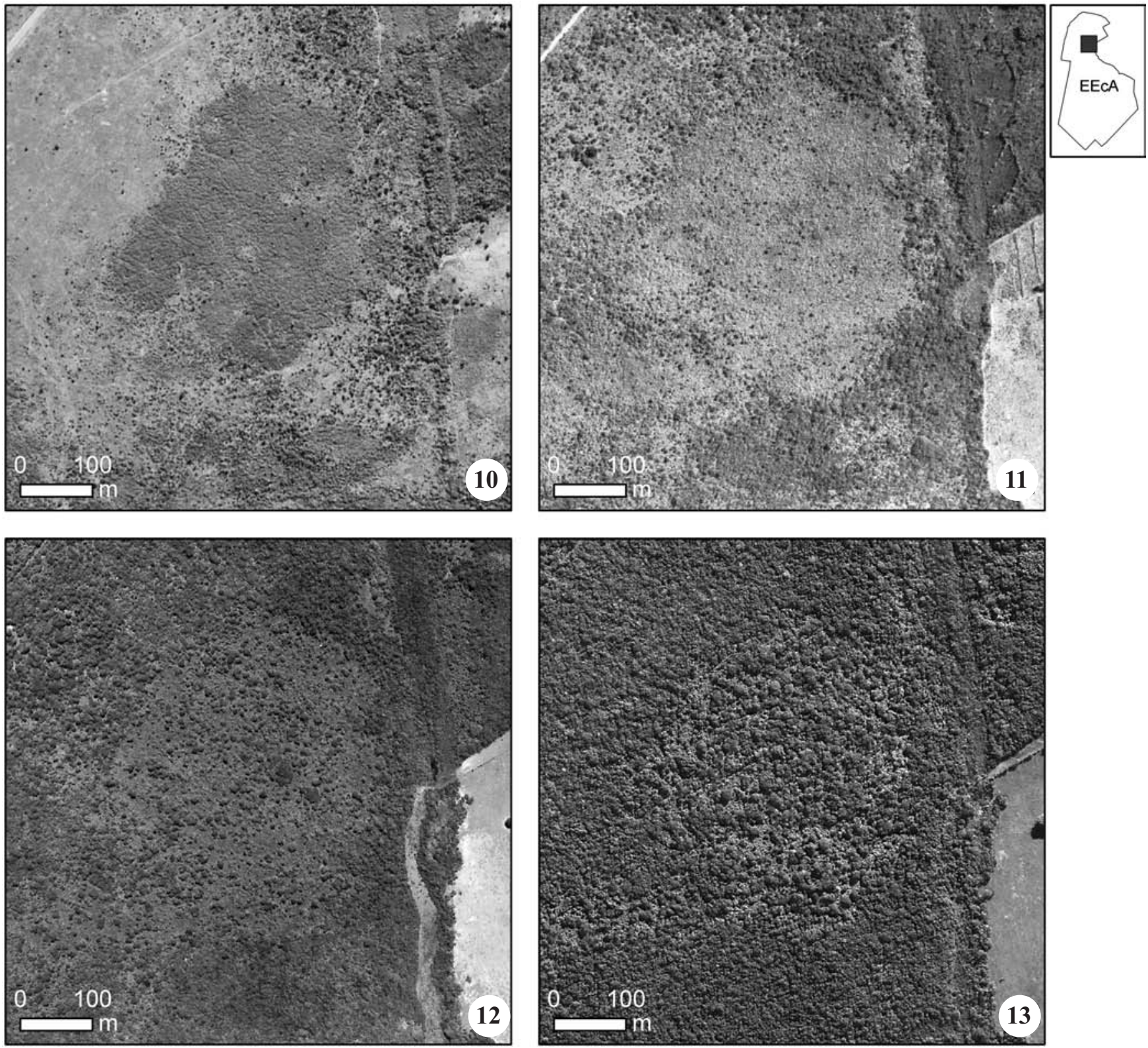

Figuras 10-13. Alterações fisionômicas na vegetação no período de 1962 a 2006, em área ocupada pela samambaia Pteridium arachnoideum. 10-12. Aerofotos $(10=1962 ; 11=1984 ; 12=1994)$. 13. imagem QuickBird (2006) (Estação Ecológica de Assis, Município de Assis, Estado de São Paulo).

Figures 10-13. Changes in the vegetation physiognomy, from 1962 to 2006, in area invaded by the fern Pteridium arachnoideum. 10-12. Aerophotos $(10=1962 ; 11=1984 ; 12=1994)$. 13. QuickBird image (2006) (Estação Ecológica de Assis, State of São Paulo, Brazil). 
ou por fisionomias savânicas em trechos situados nas porções inferiores das vertentes, onde os solos são mais arenosos e as geadas mais intensas e freqüentes (Brando \& Durigan 2004). Nas áreas ao norte da unidade, que, em 1962, demonstravam ter sofrido as mais intensas pressões antrópicas, em 2006 não existiam mais fisionomias savânicas (figuras 2-5 e 10-13). Essas áreas estão em zonas de interflúvio, mais elevadas e sobre latossolos. É possível, portanto, que a modificação mais lenta das fisionomias em alguns trechos esteja relacionada a fatores de natureza edáfica ou microclimática, com a possibilidade até de que a comunidade nunca atinja a estrutura do cerradão.

Pinheiro (2006) comparou os resultados de análises edáficas para explicar o adensamento da vegetação do Cerrado em Corumbataí, Estado de São Paulo, constatando que a disponibilidade de nutrientes no solo não é o principal elemento para explicar a mudança de cerrado sentido restrito para o cerradão. Em estudo realizado no Mato Grosso, Marimon Júnior \& Haridasan (2005) concluíram que a fertilidade do solo não é um fator determinante para explicar a coexistência de cerrado sentido restrito e cerradão. Aparentemente, segundo esses autores, a divisão do espaço pelas diferentes fisionomias está associada à disponibilidade hídrica, pois solos com teor maior de argila, comuns sob cerradão, são capazes de reter maior quantidade de água ao longo do perfil por um tempo mais longo do que solos arenosos, característicos das fisionomias mais abertas de cerrado.

Quanto à possível influência do microclima, Brando \& Durigan (2004) estudaram os efeitos da geada severa do ano 2000 sobre a vegetação da EEcA, constatando mudanças na estrutura da comunidade vegetal, similares às causadas pelo fogo, com redução da fitomassa aérea. Para esses autores, a ocorrência de geadas mais freqüentes e intensas conservaria o cerrado com fisionomias abertas, mesmo em locais onde os nutrientes e a disponibilidade hídrica poderiam sustentar uma vegetação com maior fitomassa. Assim, pode-se inferir que, embora geadas muito severas sejam esporádicas na região, com recorrência a cada 25 anos, estas e outras geadas, mais freqüentes e menos intensas, podem contribuir para a permanência de fisionomias savânicas em alguns trechos na EEcA (Brando \& Durigan 2004), que ainda persistem nas imagens de 2006, especialmente nos fundos dos vales, onde o frio é mais intenso.

Ainda que a rapidez do processo de evolução das fisionomias seja variável entre condições ambientais, o que se observou nesta unidade de conservação durante esse período de 44 anos pode ter se repetido, com maior ou menor intensidade, em todas as áreas ocupadas por vegetação de cerrado no Estado de São Paulo, que tiveram um histórico de ocupação semelhante e que se encontram sob condições de solo e clima também semelhantes. Tomando-se por base o primeiro mapeamento das fisionomias de cerrado realizado por Chiarini \& Coelho (1969), a partir do mesmo levantamento aerofotogramétrico de 1962 que foi base do presente estudo, e extrapolando-se para todo o Estado a redução aqui observada na proporção das fisionomias abertas de cerrado, estima-se que as áreas de campo cerrado e cerrado sentido restrito, que ocupavam, em 1962, 91\% do estado, se tivessem sido preservadas e protegidas contra as pressões antrópicas, teriam se reduzido a cerca de apenas $15 \%$, com o restante sendo ocupado por cerradão.

Mediante a constatação de que as perturbações antrópicas são uma constante em toda a área de domínio do Cerrado, Rizzini (1979) considera o cerrado típico como sendo um disclímax, o qual pode ser oriundo da ação prevalente do fogo (também denominado piroclímax), sendo o cerradão o verdadeiro clímax. Fernandes (2000) adota um conceito mais abrangente para o estágio de disclímax, referindo-se a uma vegetação perturbada que pode se regenerar, caso a fonte de distúrbios cesse, o que corresponde precisamente ao que se observa no Cerrado. A proposição de um climax antrópico, resultante dos padrões de uso da terra por diversas gerações de ocupantes humanos, mantendo uma comunidade arbustiva relativamente estável pela inibição do processo sucessional rumo a uma cobertura florestal, aplicado por Bouchard \& Domon (1999) no Québec, poderia, também, adequar-se à vegetação do Cerrado. A relativa estabilidade da vegetação do cerrado, associada a uma freqüência e intensidade também estáveis das perturbações, poderia, ainda, ser analisada mediante a teoria dos múltiplos estados alternativos estáveis (Sutherland 1974), em vez de se procurar identificar uma condição climácica única aceitável. A questão teórica tem implicações importantes sobre o manejo e a conservação do cerrado, uma vez que leis ambientais e políticas de conservação no Brasil têm como meta atingir e manter o clímax dos ecossistemas.

As transformações fitofisionômicas constatadas no presente estudo, se analisadas mediante os objetivos das áreas protegidas e estratégias de conservação, conduzem a um paradoxo: ou se adota o fogo como estratégia de manejo para manter a diversidade de habitats e espécies do mosaico pré-existente (estratégia de manejo defendida por Coutinho 1990, Ramos-Neto \& Pivello 2000, Miranda et al. 2004, Pivello 2005), ou se suprime o fogo, aceitando-se uma nova condição de equilíbrio, 
desconhecida, mas certamente distinta da que existia anteriormente à proteção $\mathrm{e}$, aparentemente, com redução da diversidade beta. Outras práticas de manejo, como o pastoreio ou o corte da vegetação poderiam ser também experimentados com a finalidade de manter o mosaico de fisionomias do cerrado, mas não há estudos sobre sua aplicação e efeitos.

Paralelamente às transformações estruturais constatadas, certamente estão ocorrendo transformações importantes no conjunto de espécies animais e vegetais que ocorrem na Estação Ecológica de Assis, com o aumento populacional e possível imigração de espécies adaptadas a ambientes florestais e provável extinção das não adaptadas. Cabe lembrar que o estado de fragmentação da paisagem na região pode dificultar a chegada de novas espécies, impedindo ou atrasando esse processo.

Com relação a espécies arbóreas, Giampietro (2005) verificou, em estudo da dinâmica da mata ciliar na EEcA durante 12 anos, que está ocorrendo aumento de área basal e biomassa, aumento da riqueza, ingresso de espécies oriundas da floresta estacional semidecidual e tendência à diminuição da densidade relativa ou extinção local de espécies exclusivas do cerrado. Rossato et al. (2008), em estudo sobre a flora não-arbórea da EEcA, manifestaram preocupação com a possível extinção local de espécies heliófitas e das próprias fisionomias campestres, que apresentam um grande número de espécies exclusivas.

Estudo em andamento sobre a herpetofauna desta unidade de conservação indica que a riqueza é maior e que há espécies exclusivas das fisionomias savânicas e campestres, as quais podem ser extintas se a evolução fisionômica conduzir a um clímax florestal em toda a unidade de conservação (Cybele de Oliveira Araujo, comunicação pessoal).

É possível que a preservação das espécies ameaçadas pelo desaparecimento das fisionomias campestres e savânicas seja favorecida pelo manejo do fogo em áreas de Cerrado. Por outro lado, a evolução estrutural das fisionomias da vegetação na Estação Ecológica de Assis pode representar apenas o resultado da desobstrução dos processos de dinâmica natural dos grandes biomas - cuja expansão e retração ocorrem naturalmente em resposta a mudanças climáticas globais, que viriam sendo reprimidos pelas pressões antrópicas (Durigan \& Ratter 2006). A evolução das fisionomias seria então uma adaptação à condição climática atual e, por este prisma, o processo sucessional em andamento traz em si um importante serviço ambiental até pouco tempo impensado para áreas protegidas: a fixação de carbono atmosférico.
Os resultados deste estudo mostram que, em apenas 44 anos, a área coberta por cerradão quase duplicou (tabela 1). Inúmeros trechos da unidade de conservação ocupados em 1962 por campo antrópico e cerrado ralo deram lugar a uma vegetação lenhosa com maior fitomassa e tais modificações se traduzem em aumento considerável no estoque de carbono, conforme tem sido observado também em florestas da Amazônia (Foody et al. 1996, Salomão et al. 1998). Higuchi et al. (2004) analisaram a dinâmica de uma floresta primária na Amazônia no período de 1986 a 2000, observando a acumulação $1,2 \mathrm{Mg}$ ha $^{-1}$ ano $^{-1}$ de carbono. Antes desses estudos, acreditava-se que em ecossistemas naturais protegidos o balanço entre a fixação e as emissões de carbono fosse nulo.

Mediante o cenário de aumento do efeito estufa e aquecimento global, as modificações observadas na vegetação da Estação Ecológica de Assis, portanto, são positivas e agregam a esta unidade de conservação a função adicional de sumidouro de carbono atmosférico, contribuindo para a mitigação do efeito estufa.

O paradoxo persiste e, com base no conhecimento científico vigente, não é possível assumir uma postura maniqueísta sobre o processo de evolução das fisionomias do cerrado em áreas protegidas. Há perdas e ganhos em ambos os cenários: manejando-se de forma a manter o mosaico com todo o gradiente fisionômico ou eliminando-se as interferências, de modo a permitir a dinâmica rumo a uma vegetação de maior biomassa, homogênea em toda a área.

Conforme sugerido por Bouchard \& Domon (1999), desse paradoxo emerge a oportunidade de escolher qual tipo de vegetação é desejável para o futuro. Para esses autores, os avanços da ecologia da paisagem, tanto em nível teórico como metodológico, podem contribuir para a decisão entre manejar visando manter o clímax antrópico ou permitir que a sucessão seja controlada por forças naturais. A propósito, além da conservação da diversidade biológica e do oferecimento de serviços ambientais, Estações Ecológicas, como categoria de manejo, têm como um de seus principais objetivos a pesquisa científica, admitindo, inclusive, interferências experimentais em até 3\% de sua área, pela legislação vigente (Lei Federal no 9985 de 15/07/2000, que institui o Sistema Nacional de Unidades de Conservação da Natureza). Ainda que ocupando áreas não muito extensas, unidades de conservação como a Estação Ecológica de Assis oferecem a oportunidade de que sejam estudados cientificamente os dois caminhos: a eficácia do manejo do fogo para a manutenção da diversidade biológica e o monitoramento dos processos ecológicos relacionados com a evolução dos tipos fisionômicos 
em trechos permanentemente protegidos, contribuindo efetivamente para a tomada de decisões sobre estratégias de conservação do Cerrado em larga escala.

Agradecimentos - Os autores agradecem ao Conselho Nacional do Desenvolvimento Científico e Tecnológico CNPq, pela concessão de bolsa de doutorado a E.S. Pinheiro, de produtividade em pesquisa a G. Durigan e auxílio à pesquisa, que possibilitaram a realização deste estudo.

\section{Referências bibliográficas}

ALGER, K. \& LIMA, A. 2003. Políticas públicas e a fragmentação de ecossistemas. In Fragmentação de ecossistemas: causas, efeitos sobre a biodiversidade e recomendações de políticas públicas (D.M. Rambaldi \& D.A.S. Oliveira, orgs). Ministério do Meio Ambiente, Brasília, p.390-420.

ALMEIDA, F.F.M., HASUI, Y., PONÇANO, W.L., DANTAS, A.S.L., CARNEIRO, C.D.R., MELO, M.S. \& BISTRICH, C.A. 1981. Mapa geológico do Estado de São Paulo. Escala 1:500.000. Texto explicativo. IPT, São Paulo.

ARCHER, S., SCIFRES, C. \& BASSHAN, C.R. 1988. Autogenic succession in a subtropical Savanna: Conversion of grassland to thorn woodland. Ecological Monographs 58:111-127.

BELINATO, T.A. \& MATOS, D.M.S. 2003. O impacto de Pteridium aquilinum var. arachnoideum, Pteridophyta, na germinação e morfologia de espécies arbóreas da Mata Atlântica. In Anais VI Congresso de Ecologia do Brasil, Fortaleza, p.381-383.

BOGNOLA, I.A., JOAQUIM, A.C., PRADO, H., MENK, J.R.F. \& LEPSCH,I.F. 1996. Levantamento pedológico semidetalhado da Folha de Assis. Escala 1:100.000. Secretaria da Agricultura, São Paulo.

BOUCHARD, A. \& DOMON, G. 1999. The transformations of the natural landscapes of the Haut-Saint-Laurent (Québec) and their implications on future resource management. Landscape and Urban Planning 37:99-107.

BOWMAN, D.M.J.S., WALSH, A. \& MILNE, D.J. 2001. Forest expansion and grassland contraction within a Eucalyptus savanna matrix between 1941 and 1994 at Litchfield National Park in the Australian monsoon tropics. Global Ecology \& Biogeography 10:535-548.

BRANDO, P.M. \& DURIGAN, G. 2004. Changes in cerrado vegetation after disturbance by frost (São Paulo State, Brazil). Plant Ecology 17:205-215.

CANFIELD, R.H. 1941. Application of the line interception method in sampling range vegetation. Journal of Forestry 39:388-394.

CARMEL, Y. \& KADMON, R. 1999. Effects of grazing and topography on long-term vegetation changes in a Mediterranean ecosystem in Israel. Plant Ecology 145:243-254.
CHIARINI, J.V. \& COELHO, A.G.S. 1969. Cobertura vegetal natural e áreas reflorestadas do Estado de São Paulo. Instituto Agronômico, Boletim 193. Secretaria da Agricultura do Estado de São Paulo, Campinas.

COUTINHO, L.M. 1990. O cerrado e a ecologia do fogo. Ciência Hoje 12:22-30.

DEAN, W. 1996. Aferro e fogo: a história ea devastação da Mata Atlântica brasileira. Companhia das Letras, São Paulo.

DURIGAN, G. 2006. Observations on the southern cerrados and their relationship with the core area. In Neotropical savannas and seasonally dry forests: plant diversity, biogeography and conservation (R.T. Pennington, G.P. Lewis \& J.A. Ratter, eds.). Taylor \& Francis, London, p.67-77.

DURIGAN, G. \& RATTER, J.A. 2006. Successional changes in cerradão and cerrado/forest ecotonal vegetation in western São Paulo State, Brazil, 1962-2000. Edinburgh Journal of Botany 63:119-130.

DURIGAN, G., SARAIVA, I.R., GARRIDO, M.A.O., GARRIDO, L.M.A.G. \& PECHE FILHO, A. 1987. Fitossociologia e evolução da densidade da vegetação de cerrado em Assis, SP. Boletim Técnico do Instituto Florestal 41:59-78.

DURIGAN, G., FRANCO, G.A.D.C. \& SIQUEIRA, M.F. 2004. A vegetação dos remanescentes de cerrado no estado de São Paulo. In Viabilidade de conservação dos remanescentes de cerrado no Estado de São Paulo (M.D. Bitencourt \& R.R. Mendonça, orgs.) Annablume, Fapesp. São Paulo, p.29-56.

ENVIRONMENTAL SYSTEMS RESEARCH INSTITUTE, INC. (ESRI). 2004. ArcMap. Version 9.1 [S.I.].

FEDOROV, D., FONSECA, L.M.G., KENNEY, C. \& MANJUNATH, B.S. 2003. Automatic registration and mosaicking. In Anais do XI Simpósio Brasileiro de Sensoriamento Remoto, Belo Horizonte, Inpe, São José dos Campos, p.317-324.

FERNANDES, A. 2000. Fitogeografia brasileira. Multigraf, Fortaleza.

FOODY, G.M., PALUBINSKAS, G., LUCAS, R.M., CURRAN, P.M. \& HONZAK, M. 1996. Identifying terrestrial carbon sinks: classification of sucessional stages in regenerating tropical forest from Landsat $T M$ data. Remote Sensing of Environment 55:205-216.

FRANCO, A. 2005. Biodiversidade de forma e função: implicações ecofisiológicas das estratégias de utilização de água e luz em plantas lenhosas do Cerrado. In Cerrado: ecologia, biodiversidade e conservação. (A. Scariot, J.C. Souza-Silva \& J.M. Felfili, orgs.). Ministério do Meio Ambiente, Brasília, p.179-196.

GIAMPIETRO, R. 2005. Modificações na estrutura e composição florística de matas ciliares na região do Médio Paranapanema (1992-2004). Dissertação de mestrado, Universidade de São Paulo, São Carlos.

GOODLAND, R. \& FERRI, M.G. 1979. Ecologia do Cerrado. Editora Itatiaia, Belo Horizonte, EDUSP, São Paulo. 
HENRIQUES, R.P.B. 2005. Influência da história, solo e fogo na distribuição e dinâmica das fitofisionomias no bioma do Cerrado. In Cerrado: ecologia, biodiversidade e conservação. (A. Scariot, J.C. Souza-Silva \& J.M. Felfili, orgs.). Ministério do Meio Ambiente, Brasília, p.73-92.

HIGUCHI, N., CHAMBERS, J., SANTOS, J., RIBEIRO, R.J., PINTO, A.C.M., SILVA, R.P., ROCHA, R.M. \& TRIBUZY, E.S. 2004. Dinâmica e balanço do carbono da vegetação primária da Amazônia central. Floresta 34:295-304.

HOFFMANN, W.A. 1998. Post-burn reproduction of woody plants in a neotropical savanna: the relative importance of sexual and vegetative reproduction. Journal of Applied Ecology 35:422-433.

KADMON, R. \& HARARI-KREMER, R. 1999. Studying long-term vegetation dynamics using digital processing of historical aerial photographs. Remote Sensing of Environment 68:164-176.

KLINK, C.A. \& MACHADO, R.B. 2005. A conservação do Cerrado brasileiro. Megadiversidade 1:147-155.

KÖPPEN, W. 1948. Climatologia: con un estudio de los climas de la Tierra. Fondo de Cultura Economica, México.

LILLESAND, T.M. \& KIEFER, R.W. 2000. Remote sensing and image interpretation. $4^{\text {th }}$ ed. John Wiley \& Sons, New York.

MACHADO, R.B., RAMOS NETO, M.B., PEREIRA, P.G.P., CALDAS, E.F., GONÇALVEZ, D.A., SANTOS, N.S., TABOR, K. \& STEININGER, M. 2004. Estimativas de perda de área de Cerrado brasileiro. Conservação Internacional,Brasília http://www.aja.org.br/publications /RelatDesmatamCerrado.pdf, acesso em 07/01/2009).

MARIMON JUNIOR, B.H. \& HARIDASAN, M. 2005. Comparação da vegetação arbórea e características edáficas de um cerradão e um cerrado sensu stricto em áreas adjacentes sobre solo distrófico no leste de Mato Grosso, Brasil. Acta Botanica Brasilica 19:913-926.

MARIMON,B.S.,LIMA,E.S.,DUARTE,T.G.,CHIEREGATTO, L.C. \& RATTER, J.A. 2006. Observations on the vegetation of Northeastern Mato Grosso, Brazil. IV. An analysis of the Cerrado-Amazonian forest ecotone. Edinburgh Journal of Botany 63:323-341.

MARRS, R.H., DUC, M.G., MITCKELL, R.J., GODDARD, D., PATERSON, S. \& PAKEMAN, R.J. 2000. The ecology of bracken: its role in succession and implications for control. Annals of Botany, 85 (supplement B):3-15.

MIRANDA, H.S. \& SATO, M.N. 2005. Efeitos do fogo na vegetação lenhosa do Cerrado. In Cerrado: ecologia, biodiversidade e conservação. (A. Scariot, J.C. SouzaSilva \& J.M. Felfili, orgs.). Ministério do Meio Ambiente, Brasília, p.92-104.

MIRANDA, H.S., SATO, M.N., ANDRADE, S.M.A., HARIDASAN, M., MORAIS, H.C. 2004. Queimadas de Cerrado: caracterização e impactos. In Cerrado: ecologia e caracterização (L.M.S. Aguiar \& A.J.A. Camargo, eds.). Embrapa Cerrados, Planaltina, p.69-123.
MOREIRA, A.G. 2000. Effects of fire protection on savanna structure in Central Brazil. Journal of Biogeography 27:1021-1029.

MYERS, N., MITTERMEIER, R.A., MITTERMEIER, C.G., FONSECA, G.A.B. \& KENTS, J. 2000. Biodiversity hotspots for conservation priorities. Nature 403:853858.

OLIVEIRA, J.M. \& PILLAR, V.D. 2004. Vegetation dynamics on mosaics of campos and Araucaria forest between 1974 and 1999 in Southern Brazil. Community Ecology 5:197-202.

OLIVEIRA-FILHO, A.T. \& RATTER, J.A. 2002. Vegetation physiognomies and woody flora of the Cerrado biome. In The cerrados of Brazil: ecology and natural history of a neotropical savanna (P.S. Oliveira \& R.J. Marquis, eds.). Columbia University, New York, p.91-120.

PINHEIRO, M.H.O. 2006. Composição e estrutura de uma comunidade savânica em gradiente topográfico no município de Corumbataí (SP, Brasil). Tese de doutorado, Universidade Estadual Paulista, Rio Claro.

PIVELLO, V.R. 2005. Manejo de fragmentos de Cerrado: princípios para a conservação da biodiversidade. In Cerrado: ecologia, biodiversidade e conservação. (A. Scariot, J.C. Souza-Silva \& J.M. Felfili, orgs.). Ministério do Meio Ambiente, Brasília, p.401-413.

RAMOS-NETO, M.B. \& PIVELLO, V.R. 2000. Lightning fires in a Brazilian savanna national park: rethinking management strategies. Environmental Management 26:675-684.

RATTER, J.A. 1992. Transitions between cerrado and Forest vegetation in Brazil. In Nature and dynamics of ForestSavanna boundaries (P.A. Furley, J. Proctor \& J.A. Ratter, eds.). Chapman \& Hall, London, p.417-430.

RATTER, J.A., BRIDGEWATER, S. \& RIBEIRO, F. 2006. Biodiversity patterns of the woody vegetation of the Brazilian Cerrado. In Neotropical savannas and seasonally dry forests: plant diversity, biogeography and conservation (R.T. Pennington, G.P. Lewis \& J.A. Ratter, eds.). Taylor \& Francis, London, p.31-65.

RATTER, J.A., LEITÃO FILHO, H.F., AGENT, G., GIBBS, P.E., SEMIR, J., SHEPHERD, G.J. \& TAMASHIRO, J. 1988. Floristic composition and community structure of a southern cerrado area in Brazil. Notes of the Royal Botanic Garden Edinburgh 45:137-151.

RESEARCH SYSTEMS INC. (RSI). 2006. ENVI user's guide: research systems project for ENVI (Environment for visualizing Images). Version 4.3. Boulder: RSI, CDROM.

RIBEIRO, J.R. \& WALTER, B.M.T. 1998. Fitofisionomias do bioma Cerrado. In Cerrado: ambiente e flora. (S.M. Sano \& S.P. Almeida, eds.). Embrapa-CPAC, Planaltina, p.89-166.

RIZZINI, C.T. 1979. Tratado de fitogeografia do Brasil: aspectos sociológicos e florísticos. Hucitec-Edusp, São Paulo. 
ROSSATTO, D.R., TONIATO, M.T.Z. \& DURIGAN, G. 2008. Flora fanerogâmica não-arbórea do cerrado na Estação Ecológica de Assis, Estado de São Paulo. Revista Brasileira de Botânica 31:409-424.

SALOMÃO, R.P., NEPSTAD, D.C. \& VIEIRA, I.C. 1998. Biomassa e estoque de carbono de florestas tropicais primárias e secundárias. In Floresta Amazônica: dinâmica, regeneração e manejo (C. Gascon \& P. Moutinho, orgs.). Inpa, Manaus, p.99-119.
SPURR, S.H. \& BARNES, B.V. 1980. Forest ecology. John Wiley and Sons Inc., New York.

SUTHERLAND, J.P. 1974. Multiple stable points in natural communities. American Naturalist 108: 859-873.

TAO, V. \& HU, Y. 2001. A comprehensive study of the rational function model for photogrammetric processing. Protogrammetric Engineering and Remote Sensing $67: 1347-1357$. 